\title{
Positron Emission Tomography-Computed Tomography Coregistration for Diagnosis and Intraoperative Localization in Recurrent Nelson Syndrome
}

\author{
Eric B. Hintz ${ }^{1}$ Jeffery M. Tomlin ${ }^{2}$ Vaseem Chengazi ${ }^{3}$

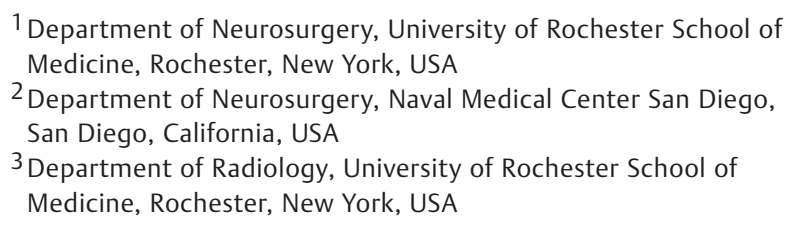

G. Edward Vates ${ }^{1}$

Address for correspondence Eric B. Hintz, MD, 601 Elmwood Ave, Box 670, Rochester, NY 14642, USA

(e-mail: Eric_Hintz@urmc.rochester.edu).

J Neurol Surg Rep 2013;74:33-36.

\author{
Abstract \\ Keywords \\ - computed \\ tomography \\ - Nelson syndrome \\ - pituitary adenoma \\ - positron emission \\ tomography
}

Recurrent pituitary disease presents unique challenges, including in some cases difficulty localizing a tumor radiographically. Here, we present the case of a patient with recurrent Nelson syndrome whose radiographic work-up was complicated by a significant parasellar metallic artifact. Positron emission tomography ultimately localized the lesion, and coregistration with computed tomography allowed for accurate intraoperative navigation. Additionally, we review a range of imaging techniques available in the evaluation of pituitary disease.

\section{Introduction}

Nelson syndrome is a rare condition defined by enlargement of a pituitary adenoma following bilateral adrenalectomy for treatment of Cushing disease. ${ }^{1}$ The incidence of Nelson syndrome in adults varies between 8 and $29 \%,{ }^{2}$ but it may be seen more frequently in patients who undergo adrenalectomy at a younger age. ${ }^{3}$ The pathophysiology of the disease is complex and controversial, ${ }^{1,2,4}$ and it is unknown what factors drive corticotroph cells in these patients. Blood tests showing rising adrenocorticotropic hormone (ACTH) levels and imaging showing an enlarging pituitary mass confirm the diagnosis. ${ }^{4}$ Treatment depends on surgery and/or radiotherapy. ${ }^{1,4,5} \mathrm{We}$ present the case of a patient with recurrent Nelson syndrome whose effective treatment requires novel imaging due to prior sellar reconstruction with a metal plate; this case suggests that metabolic radionuclide imaging may be a new option for managing patients with Nelson syndrome.

\section{Case Presentation}

In 1968, the then 8-year-old patient underwent bilateral adrenalectomy for treatment of Cushing disease. Four years later, she developed bitemporal hemianopsia, was found to have increased $\mathrm{ACTH}$, and was diagnosed with Nelson syndrome. After external beam radiation and transsphenoidal decompression of her tumor, a right frontal craniotomy for tumor resection and hypophysectomy provided symptomatic relief until 1983, when her ACTH again began to rise. Transsphenoidal exploration failed to find tumor; the surgeon reconstructed the sellar floor with metallic mesh encased in methyl methacrylate. The following year, another endonasal exploration found tumor along the anterior clivus. Her ACTH normalized until 1998, when another successful endonasal tumor resection was performed. In 2002, the patient underwent a craniotomy for resection of a radiation-induced left frontal meningioma.
DOI http://dx.doi.org/ $10.1055 / \mathrm{s}-0033-1346974$. ISSN 2193-6358. 

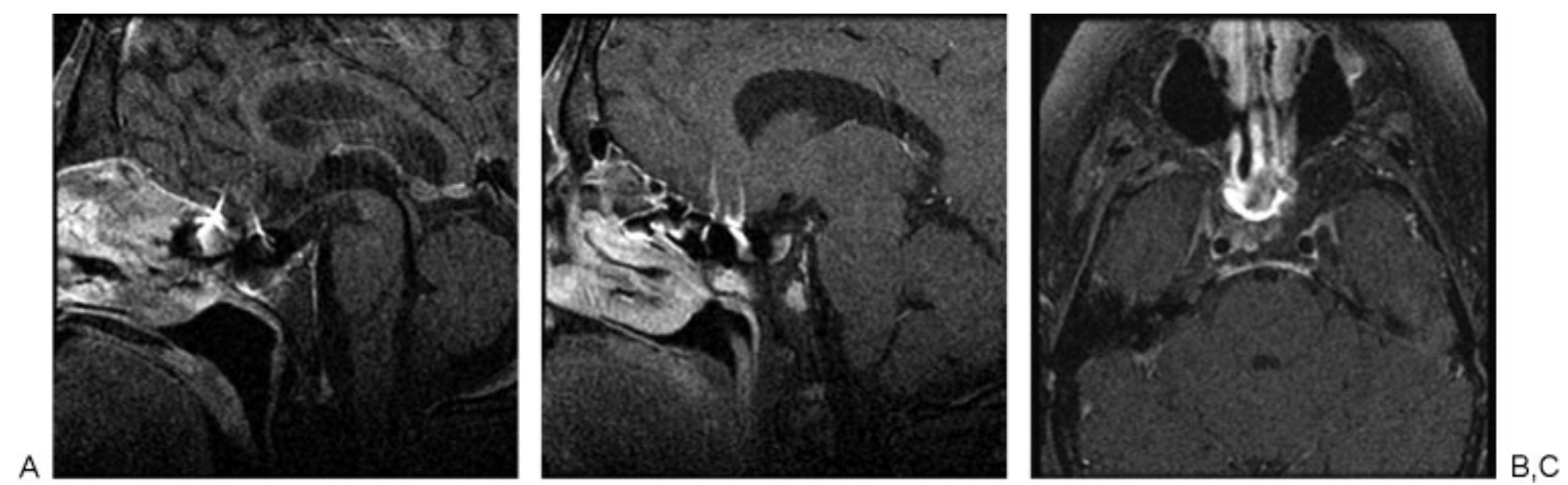

Fig. 1 T1-weighted postgadolinium magnetic resonance imaging (MRI). (A) Midline sagittal. (B) Left paramedian sagittal. (C) Axial. Concern for residual tumor along sellar floor seen in (A) and (C), as well as within the sphenoidal body (B). Note metallic artifact in all three images.

In 2005 , at the age of 45 , she presented with a clinical spectrum characteristic of past ACTH overabundance: skin pigmentation, retro-orbital headache, and mouth ulcers. Her ACTH was measured at greater than $3,000 \mathrm{pg} / \mathrm{mL}$ (normal range 0 to $46 \mathrm{pg} / \mathrm{mL}$ ). On exam, she had bitemporal hemianopsia and slightly restricted lateral gaze. Pituitary-protocol magnetic resonance imaging (MRI) demonstrated two potential sites of recurrent tumor: one adjacent to the sella and a second lower on the clivus. Metallic artifact from the previously placed mesh made interpretation of the study difficult (-Fig. 1).

To better elucidate which region may have been responsible for her elevated ACTH, the patient was sent for octreotide scintigraphy. Despite poor spatial resolution, this implicated the more rostral lesion. Given the anticipated difficulty of yet another surgery, our first recommendation was radiosurgery. However, in light of her radiation-induced meningioma, the patient refused radiosurgical treatment and insisted on pursing surgical options.

The patient then underwent a fludeoxyglucose positron emission tomography (FDG PET) scan with fine-cut computed tomography (CT) coregistration to better delineate her tumor and adjacent bony landmarks. As seen in - Fig. 2, the anatomic relationship between the area of increased glucose uptake and the sellar floor was well defined. She underwent an endonasal transsphenoidal microscopic approach. To assist intraoperative navigation, the CT was imported to the Brainlab neuronavigation system (Brainlab AG, Feldkirchen,
Germany). During surgery, the mesh plate was found encased with scar and carefully removed. With the aid of intraoperative navigation (-Fig. $\mathbf{3}$ ), the left floor of the sella was explored; a bony crevice was found, and pathologic tissue within it was removed. Using gentle suction and various ring curettes, all tissue within the osseous cave was carefully freed and evacuated. Pathologic review of the tissue confirmed ACTH-positive tumor. Her postoperative course was uneventful, and she was discharged home on postoperative day 4. At her first postoperative visit 1 week after discharge, her headaches had resolved, her skin tone began lightening, and she had resumed her preoperative activities. Serial ACTH levels dropped precipitously, eventually reaching a nadir of $90 \mathrm{pg} /$ $\mathrm{mL}$. She remained asymptomatic for the remainder of her life before succumbing to complications from acute myeloleukemia in 2010.

\section{Discussion}

A significant number of patients face the specter of pituitary tumor recurrence. Rates of recurrence differ according to tumor pathology, ${ }^{6}$ but it has been suggested that patients with prior target gland destruction, as in patients with Nelson syndrome, face higher recurrence rates due to loss of inhibitory feedback. ${ }^{7}$ In one large series, rates of recurrence for ACTH tumors was $12 \%$, whereas $25 \%$ of those with Nelson syndrome faced recurrence within 10 years. $^{6}$
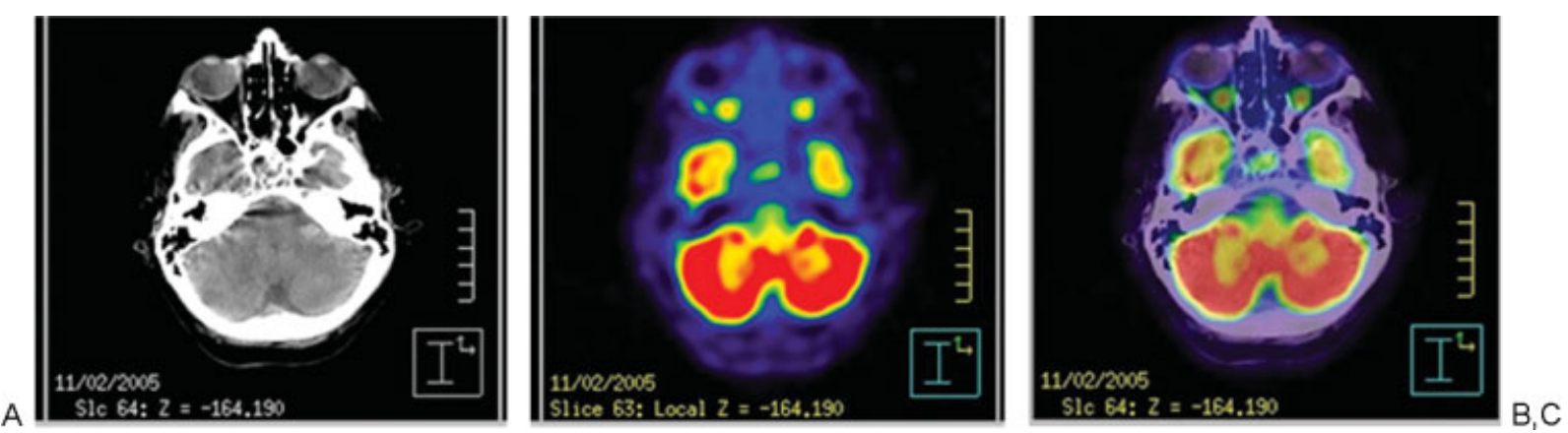

Fig. 2 (A) Fine-cut axial computed tomography (CT). (B) 18-Fludeoxyglucose positron emission tomography (FDG PET). (C) Coregistration overlay demonstrating area of increased glucose uptake along the floor of the sella to the left of midline. 

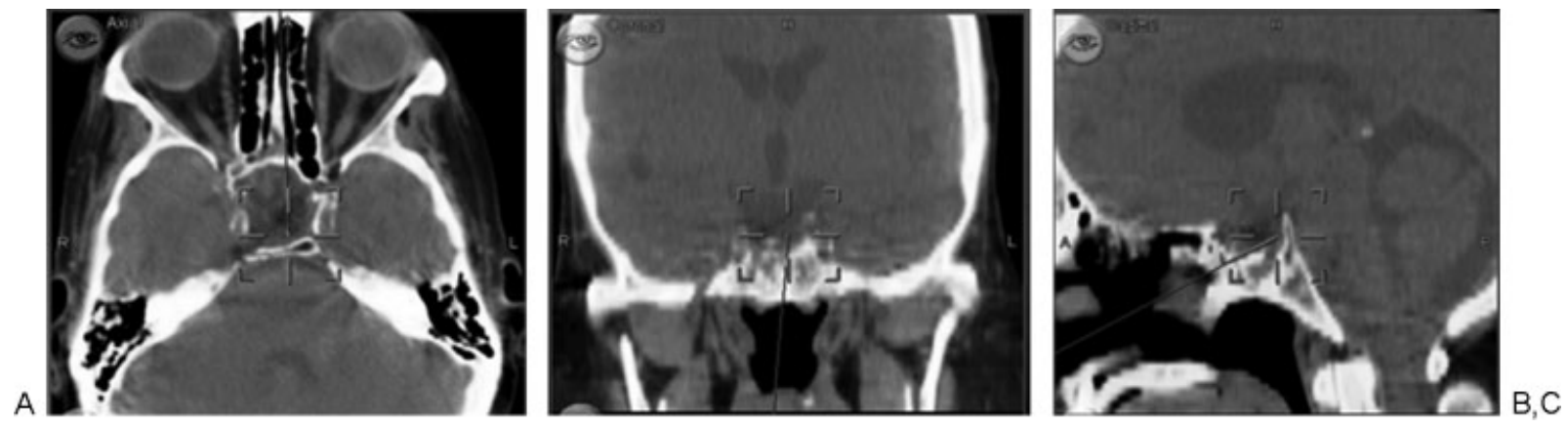

Fig. 3 Intraoperative screen shot from Brainlab neuronavigation system (Brainlab AG, Feldkirchen, Germany) displaying a registered probe placed at the spot suggested by coregistration in (A) axial, (B) coronal, and (C) sagittal projections.

In the work-up of both de novo and recurrent disease, MRI is the imaging modality of choice. Unfortunately, reliable direct visualization of microadenomas is limited to tumors greater than $4 \mathrm{~mm}$. Advanced imaging techniques, such as dynamic scanning and delayed postcontrast images, can depict smaller adenomas, but there is a huge potential for misinterpretation. ${ }^{8}$ Thus, ACTH-secreting adenomas, which are frequently very small, are correctly identified by MRI in only about half of cases. ${ }^{9}$ Additionally, for a subset of patients, MRI may be contraindicated. Contraindications may include ferromagnetic implants ${ }^{10}$ or severe patient claustrophobia. Furthermore, imaging of the sella and its contents may be compromised by parasellar metallic artifact from either concomitant previously treated aneurysms ${ }^{11}$ or as a result of previous sellar surgery. In the latter case, metallic artifact may stem from metallic mesh used during buttress repair of the sellar floor ${ }^{12,13}$ or metallic debris from prior drilling. ${ }^{14}$

If MRI is contraindicated or provides insufficient image quality for any of the aforementioned reasons, alternate imaging modalities must be considered. CT scans, which are routinely ordered to provide surgeons valuable osseous anatomic detail for purposes of operative planning, may be used to visualize sellar-regions tumors, particularly when contrast is administered. ${ }^{15}$ Even on older generation machines, the spatial resolution of CT scanners has allowed for the detection microadenomas as small as 3 to $4 \mathrm{~mm},{ }^{16}$ but the poor sensitivity of CT for microadenoma detection does not allow this to be done reliably. ${ }^{17}$ CT scans, like MRI, are susceptible to metallic artifact that may degrade image quality $^{18}$ in patients who have had prior attempts at resection.

Scintigraphy, particularly with ${ }^{111}$ In-octreotide, may also aid in the diagnosis of pituitary adenomas. Scintigraphy is a nuclear medicine imaging test in which cameras capture emitted radiation from previously administered radioisotopes to form two-dimensional images. Octreotide is a somatostatin analog that binds to several somatostatin receptor subtypes. ${ }^{19}$ The normal anterior pituitary gland contains these octreotide-binding somatostatin receptor subtypes, but techniques have been developed to detect additional uptake from pituitary adenomas. ${ }^{20}$ Importantly, somatostatin receptor expression, and consequentially scintigraphy visualization, differs by adenoma type. A high proportion of growth hormone-and thyroid-stimulating hormone-secreting tumors are visualized after ${ }^{111}$ In-octreotide administration, whereas prolactin and nonfunctioning adenomas display variable somatostatin receptor expression. ${ }^{21,22}$ ACTH-secreting tumors present a slightly more complicated picture. In patients with newly diagnosed Cushing disease, tumors do not demonstrate increased uptake, ${ }^{23}$ but a majority of recurrent ACTH-secreting tumors are visualized. ${ }^{22}$ It has been speculated that this difference may be due to decreased somatostatin receptor expression in the setting of long-term cortisol exposure. $^{23}$

PET scans are another nuclear medicine study in which gamma rays are detected from previously administered radiotracers linked to biologically active molecules. In some cases PET nucleotides have been used to measure expression of specific receptors, such as dopamine, ${ }^{24}$ or enzymes, such as monoamine oxidase B. ${ }^{25}$ Much more frequently used, however, are nucleotides targeted at the more general measures of glucose uptake, via the glucose analog FDG, or anabolism, via the amino acid analog ${ }^{11} \mathrm{C}$-methionine. Both have found value in the detection of pituitary adenomas, ${ }^{26-34}$ but ${ }^{11} \mathrm{C}$ methionine may have greater utility in detecting microadenomas. ${ }^{29}$ Additional diagnostic utility imaging has been gained by coregistering axial PET images with either $\mathrm{CT}^{35}$ or MRI. ${ }^{36}$ However, although PET coregistration with either $\mathrm{MRI}^{37-39}$ or $\mathrm{CT}^{40}$ has been used in intraparenchymal tumor surgery, this is the first report of PET coregistration in the setting of pituitary tumor.

\section{Disclosure from Dr. Tomlin}

The views expressed in this article are my own and do not necessarily reflect the official policy or position of the Department of the Navy, Department of Defense, or the U.S. Government.

\section{References}

1 Banasiak MJ, Malek AR. Nelson syndrome: comprehensive review of pathophysiology, diagnosis, and management. Neurosurg Focus 2007;23(3):E13

2 Assié G, Bahurel H, Bertherat J, Kujas M, Legmann P, Bertagna X. The Nelson's syndrome... revisited. Pituitary 2004;7(4):209-215 
3 Kemink L, Pieters G, Hermus A, Smals A, Kloppenborg P. Patient's age is a simple predictive factor for the development of Nelson's syndrome after total adrenalectomy for Cushing's disease. J Clin Endocrinol Metab 1994;79(3):887-889

4 Barber TM, Adams E, Ansorge O, Byrne JV, Karavitaki N, Wass JA. Nelson's syndrome. Eur J Endocrinol 2010;163(4):495-507

5 Munir A, Newell-Price J. Nelson's Syndrome. Arq Bras Endocrinol Metabol 2007;51(8):1392-1396

6 Dunn IF, Laws ER Jr. Transsphenoidal surgery for recurrent disease. In: Laws ER Jr., Lanzino G, eds. Transsphenoidal Surgery. Philadelphia, PA: Saunders; 2010:192-199

7 Thapar K, Kovacs K, Muller PJ. Clinical-pathological correlations of pituitary tumours. Baillieres Clin Endocrinol Metab 1995;9 (2):243-270

8 Buchfelder M, Schlaffer SM. Modern imaging of pituitary adenomas. Front Horm Res 2010;38:109-120

9 Batista D, Courkoutsakis NA, Oldfield EH, et al. Detection of adrenocorticotropin-secreting pituitary adenomas by magnetic resonance imaging in children and adolescents with cushing disease. J Clin Endocrinol Metab 2005;90(9):5134-5140

10 Shellock FG, Spinazzi A. MRI safety update 2008: part 2, screening patients for MRI. AJR Am J Roentgenol 2008;191(4):1140-1149

11 Pant B, Arita K, Kurisu K, Tominaga A, Eguchi K, Uozumi T. Incidence of intracranial aneurysm associated with pituitary adenoma. Neurosurg Rev 1997;20(1):13-17

12 Zada G, Kelly DF, Cohan P, Wang C, Swerdloff R. Endonasal transsphenoidal approach for pituitary adenomas and other sellar lesions: an assessment of efficacy, safety, and patient impressions. J Neurosurg 2003;98(2):350-358

13 Cook SW, Smith Z, Kelly DF. Endonasal transsphenoidal removal of tuberculum sellae meningiomas: technical note. Neurosurgery 2004;55(1):239-244, discussion 244-246

14 Fahlbusch R, Gerganov VM. Non-functional pituitary tumors. In: Kaye AH, Laws ER Jr., ed. Brain Tumors: An Encyclopedic Approach. Third Edition. Edinburg: Saunders; 2012:672-691

15 Zimmerman RA. Imaging of intrasellar, suprasellar, and parasellar tumors. Semin Roentgenol 1990;25(2):174-197

16 Syvertsen A, Haughton VM, Williams AL, Cusick JF. The computed tomographic appearance of the normal pituitary gland and pituitary microadenomas. Radiology 1979;133(2):385-391

17 Kulkarni MV, Lee KF, McArdle CB, Yeakley JW, Haar FL. 1.5-T MR imaging of pituitary microadenomas: technical considerations and CT correlation. AJNR Am J Neuroradiol 1988;9(1):5-11

18 van der Schaaf I, van Leeuwen M, Vlassenbroek A, Velthuis B. Minimizing clip artifacts in multi CT angiography of clipped patients. AJNR Am J Neuroradiol 2006;27(1):60-66

19 Moulik PK, Varma TR, Vora JP, Vinjamuri S. The role of somatostatin receptor scintigraphy in the management of pituitary tumours. Nucl Med Commun 2002;23(2):117-120

20 van Royen EA, Verhoeff NP, Meylaerts SA, Miedema AR. Indium111-DTPA-octreotide uptake measured in normal and abnormal pituitary glands. J Nucl Med 1996;37(9):1449-1451

21 Warner RR, O'dorisio TM. Radiolabeled peptides in diagnosis and tumor imaging: clinical overview. Semin Nucl Med 2002;32 (2):79-83

22 Acosta-Gómez MJ, Muros MA, Llamas-Elvira JM, et al. The role of somatostatin receptor scintigraphy in patients with pituitary adenoma or post-surgical recurrent tumours. $\mathrm{Br} \mathrm{J}$ Radiol 2005;78(926):110-115

23 de Herder WW, Krenning EP, Malchoff CD, et al. Somatostatin receptor scintigraphy: its value in tumor localization in patients with Cushing's syndrome caused by ectopic corticotropin or corticotropin-releasing hormone secretion. Am J Med 1994;96 (4):305-312

24 de Herder WW, Reijs AE, Feelders RA, et al. Diagnostic imaging of dopamine receptors in pituitary adenomas. Eur J Endocrinol 2007;156(Suppl 1):S53-S56

25 Bergström M, Muhr C, Jossan S, Lilja A, Nyberg G, Långström B. Differentiation of pituitary adenoma and meningioma: visualization with positron emission tomography and [11C]-L-deprenyl. Neurosurgery 1992;30(6):855-861

26 Taguchi T, Takao T, Iwasaki Y, et al. Diagnostic value of $18 \mathrm{~F}$ dihydroxyphenylalanine positron emission tomography for growth hormone-producing pituitary adenoma. Pituitary 2010;13(1):78-79

27 Tang BN, Levivier M, Heureux M, et al. 11C-methionine PET for the diagnosis and management of recurrent pituitary adenomas. Eur J Nucl Med Mol Imaging 2006;33(2):169-178

28 De Souza B, Brunetti A, Fulham MJ, et al. Pituitary microadenomas: a PET study. Radiology 1990;177(1):39-44

29 Muhr C. Positron emission tomography in acromegaly and other pituitary adenoma patients. Neuroendocrinology 2006;83(34):205-210

30 Jeong SY, Lee SW, Lee HJ, et al. Incidental pituitary uptake on whole-body 18F-FDG PET/CT: a multicentre study. Eur J Nucl Med Mol Imaging 2010;37(12):2334-2343

31 Hyun SH, Choi JY, Lee KH, Choe YS, Kim BT. Incidental focal 18FFDG uptake in the pituitary gland: clinical significance and differential diagnostic criteria. J Nucl Med 2011;52(4):547-550

32 Komori T, Martin WH, Graber AL, Delbeke D. Serendipitous detection of Cushing's disease by FDG positron emission tomography and a review of the literature. Clin Nucl Med 2002;27(3):176-178

33 Bergström M, Muhr C, Lundberg PO, Långström B. PET as a tool in the clinical evaluation of pituitary adenomas. J Nucl Med 1991;32 (4):610-615

34 Campeau RJ, David O, Dowling AM. Pituitary adenoma detected on FDG positron emission tomography in a patient with mucosaassociated lymphoid tissue lymphoma. Clin Nucl Med 2003;28 (4):296-298

35 Alzahrani AS, Farhat R, Al-Arifi A, Al-Kahtani N, Kanaan I, Abouzied $M$. The diagnostic value of fused positron emission tomography/ computed tomography in the localization of adrenocorticotropinsecreting pituitary adenoma in Cushing's disease. Pituitary 2009; 12(4):309-314

36 Ikeda H, Abe T, Watanabe K. Usefulness of composite methioninepositron emission tomography/3.0-tesla magnetic resonance imaging to detect the localization and extent of early-stage Cushing adenoma. J Neurosurg 2010;112(4):750-755

37 Pirotte B, Goldman S, Dewitte O, et al. Integrated positron emission tomography and magnetic resonance imaging-guided resection of brain tumors: a report of 103 consecutive procedures. J Neurosurg 2006;104(2):238-253

38 Ewelt C, Floeth FW, Felsberg J, et al. Finding the anaplastic focus in diffuse gliomas: the value of Gd-DTPA enhanced MRI, FET-PET, and intraoperative, ALA-derived tissue fluorescence. Clin Neurol Neurosurg 2011;113(7):541-547

39 Pirotte BJ, Lubansu A, Massager N, et al. Clinical impact of integrating positron emission tomography during surgery in 85 children with brain tumors. J Neurosurg Pediatr 2010;5(5): 486-499

40 Yang S, Zhang C, Zhu T, et al. Resection of gliomas using positron emission tomography/computed tomography neuronavigation. Neurol Med Chir (Tokyo) 2007;47(9):397-401, discussion 402 